\title{
Anti-Carbonic Anhydrase II Antibodies in End-Stage Renal Disease Patients
}

\author{
Ahmet Alver $^{\mathrm{a}}$ Ahmet Menteşe ${ }^{\mathrm{a}, \mathrm{c}}$ Ümit Menteşe ${ }^{\mathrm{d}}$ Ayşegül Sümer $^{\mathrm{a}}$ \\ Fahri Uçar ${ }^{\text {b }}$ Diler Us Altay ${ }^{a}$ \\ Departments of a Medical Biochemistry and ${ }^{b}$ Medical Biology and Genetics, Faculty of Medicine, and ${ }^{c}$ Program \\ of Medical Laboratory Techniques, Vocational School of Health Sciences, Karadeniz Technical University, and \\ ${ }^{\mathrm{d}}$ Department of Cardiovascular Surgery, Ahi Evren Thoracic and Cardiovascular Surgery Training and Research \\ Hospital, Trabzon, Turkey
}

\section{Key Words}

End-stage renal disease - Carbonic anhydrase II .

Malondialdehyde · Autoimmunity. Ghrelin

\begin{abstract}
Objective: The aim of this study was to investigate the presence of anti-carbonic anhydrase (CA II) autoantibodies in patients with end-stage renal disease (ESRD) and relationships between the autoantibody titers and ghrelin, glucose, blood urea nitrogen (BUN) and creatinine. Subjects and Methods: Serum CA II autoantibody titers, malondialdehyde (MDA), BUN, creatinine and ghrelin levels were measured in 45 ESRD patients and 45 healthy subjects. Results: The CA II autoantibody titers in the ESRD group $(0.170 \pm 0.237)$ were significantly higher than those in the control group $(0.079 \pm 0.032$; $p=0.035)$. MDA and ghrelin levels were also significantly higher in the ESRD group $(p<0.001)$. A weak positive correlation was determined between anti-CA II antibody titers and MDA, and a negative correlation was observed between ghrelin levels and anti-CA II antibody titers $(r=0.287, p=$ 0.028 and $r=-0.278, p=0.032$, respectively). Conclusions: In ESRD patients, the results showed the development of an autoimmune response against CA II. This suggests that antiCA II antibodies could be involved in the pathogenesis of ESRD.

๑) 2014 S. Karger AG, Basel
\end{abstract}

\section{Introduction}

Carbonic anhydrase (CA; EC 4.2.1.1) is a zinc-containing enzyme. Sixteen CA isoenzymes with different tissue distributions and cellular localizations have been described in mammals. Fourteen of these catalyze the reversible hydration of carbon dioxide to bicarbonate and the other two do not exhibit catalytic activity. The catalytic reaction plays important physiological roles, including $\mathrm{CO}_{2}$ transport, ion secretion, $\mathrm{pH}$ regulation and calcification [1]. The presence of certain CA isoenzymes (CA II, CA IV, CA VB and CA XII) at different cellular locations in the human kidney has been demonstrated. These are crucial for at least three physiological processes: $\mathrm{pH}$ regulation (by secreting and excreting protons due to the carbon dioxide hydration reaction catalyzed by the enzymes), the bicarbonate reabsorption process and ammonium ion output [2]. Recent studies have shown the formation of an autoimmune response against the CA II isoenzyme in several diseases [3-6] including Sjögren's syndrome (SJS). The high urinary $\mathrm{pH}$ levels and renal tubular acidosis observed in this syndrome were attributed to that of the CA II autoantibodies [7]. In another case, CA II antibodies were detected in patients with autoimmune pancreatitis with tubulointerstitial nephritis [8]. The mechanism responsible for autoantibody formation

\begin{tabular}{ll}
\hline KARGER & $\begin{array}{l}\text { () 2014 S. Karger AG, Basel } \\
1011-7571 / 14 / 0234-0331 \$ 39.50 / 0 \quad \text { Karger }\end{array}$ \\
$\begin{array}{l}\text { E-Mail karger@karger.com } \\
\text { www.karger.com/mpp }\end{array}$ & $\begin{array}{l}\text { This is an Open Access article licensed under the terms of the } \\
\text { Creative Commons Attribution-NonCommercial 3.0 Un- } \\
\text { ported license (CC BY-NC) (www.karger.com/OA-license), } \\
\text { applicable to the online version of the article only. Distribu- } \\
\text { tion permitted for non-commercial purposes only. }\end{array}$
\end{tabular}

Ahmet Alver, $\mathrm{PhD}$

Department of Medical Biochemistry, Faculty of Medicine

Karadeniz Technical University

TR-61080 Trabzon (Turkey)

E-Mail alver61@yahoo.com 
has not yet been identified, though it has been suggested that oxidative stress may be involved [9].

Patients with end-stage renal disease (ESRD) are exposed to powerful oxidative stress as a result of increased prooxidant capacity and a weakened antioxidant defense system. A chronic inflammatory state, advanced age, diabetes, uremic syndrome, leukocyte activation due to hemodialysis and the use of iron associated with anemia treatment are the main sources of oxidative stress in these patients $[10,11]$. Malondialdehyde (MDA), the end product of lipid peroxidation and an important marker of in vivo oxidative status, is elevated in ESRD patients [12]. Studies have reported that oxidative stress is correlated with complications of ESRD such as atherosclerosis, dialysis-related amyloidosis, malnutrition and anemia [13]. Directly or indirectly, reactive oxygen species modify biomolecules including carbohydrates, proteins and DNA, contribute to the expansion of oxidative injury and may also trigger the initiation of the autoimmune process [14].

Ghrelin is an orexigenic peptide consisting of 28 amino acids and is mainly produced in endocrine cells in the stomach. It enhances appetite and regulates the long- and short-term energy balance. It is broken down by the kidneys and plays a significant role in the regulation of energy homeostasis, systemic inflammation and the cardiovascular system [15]. It is important in the pathogenesis of protein-energy wasting, systemic inflammation and cardiovascular complications in ESRD, all of which are significantly associated with patient outcomes including mortality $[16,17]$.

The existence of anti-CA II autoantibody in sera obtained from ESRD patients has not yet been reported. The objective of this study was to investigate the presence of anti-CA II antibodies in patients with ESRD and determine relationships between the autoantibody titers and other clinical parameters (ghrelin, glucose, BUN and creatinine) and discuss a possible role of anti-CA II antibody in the pathogenesis of ESRD.

\section{Materials and Methods}

\section{Study Population}

After receiving approval from the institutional ethics committee, informed consent was obtained from all patients and controls. The study enrolled 45 ESRD patients undergoing hemodialysis (3 times a week) as the study group and 45 healthy peers as the control group.

Exclusion criteria were: (1) acute ischemic diseases including acute coronary syndrome, acute ischemic cerebrovascular disease, acute peripheral arterial occlusion or acute mesenteric ischemia; (2) advanced liver or heart failure; (3) asymptomatic coronary ischemia, for which ECG testing was performed; (4) age $<18$ years; (5) patients starting hemodialysis for the first time, and (6) refusal to participate in the study. The healthy controls were selected according to their self-reported medical histories based on age and gender distribution.

Prehemodialysis blood samples $(3-5 \mathrm{ml})$ for each patient and healthy volunteer were collected in vacutainer tubes containing separation gels. After clotting, blood samples were centrifuged at $3,000 \mathrm{rpm}$ for $10 \mathrm{~min}$. Serum samples were stored at $-80^{\circ} \mathrm{C}$ until biochemical measurements were made.

Ghrelin (total ghrelin) was measured using commercial ELISA kits (Phoenix Pharmaceuticals, USA). Glucose, BUN and creatinine were measured using an autoanalyzer.

Enzyme-Linked Immunosorbent Assay for Serum

Autoantibody to CA II

Human CA II, electrophoretically purified from erythrocytes, was obtained from Sigma Chemical Co. (St. Louis, Mo., USA). Plasma anti-CA II was detected using ELISA following a previously described method [5]. Briefly, microtiter plates (high-binding, flatbottomed plates; Deltalab, Spain) were coated with $50 \mu \mathrm{l}$ of 10 $\mu \mathrm{g} / \mathrm{ml}$ CA II in carbonate buffer $(0.05 \mathrm{mM}, \mathrm{pH} 9.6)$ and incubated overnight at $4^{\circ} \mathrm{C}$. The wells were washed 4 times with phosphate buffer (pH 7) and blocked with $2 \%$ skim milk in phosphate buffer for $2 \mathrm{~h}$ at room temperature (RT). After being washed 4 times with phosphate buffer containing $0.05 \%$ Tween-20, the wells were incubated with $100 \mu \mathrm{l}$ of serum diluted with blocking buffer (1:200) for $2 \mathrm{~h}$ at RT. After washing, each well was incubated for $2 \mathrm{~h}$ at RT with $100 \mu \mathrm{l}$ of 1:2,000 dilution of peroxidase-conjugated anti-human IgG anti-serum (Sigma) in blocking buffer. Following 5 washes with phosphate buffer containing $0.05 \%$ Tween-20, the wells were incubated with $100 \mu \mathrm{l}$ of substrate solution for $20 \mathrm{~min}$ at RT. The reaction was stopped by the addition of $100 \mu \mathrm{l}$ of $2 \mathrm{M} \mathrm{H}_{2} \mathrm{SO}_{4}$ to each well. The absorbance was read at $480 \mathrm{~nm}$ (VersaMax, Molecular Devices, Sunnyvale, Calif., USA). Control wells that were not coated with CA II were also used for the ELISA of each serum studied. All assays were performed in duplicate, and the specific binding of serum antibody to CA II was calculated as follows: the average absorbance of the antigen-coated wells minus the average absorbance of control wells: specific binding $=\mathrm{A}_{\text {coated }}-\mathrm{A}_{\text {contol }}$.

Samples from an ESRD patient and a control subject were used for the determination of the intra-assay coefficient of variation. For the anti-CA II antibody assay, the intra-assay coefficient of variation was $5.8 \%(n=5)$ in the ESRD patient and $3.9 \%(n=5)$ in the control.

\section{MDA Measurements}

Lipid peroxidation in serum samples was determined as MDA concentration using the method described by Yagi [18]. Tetramethoxypropane was used as a standard, and MDA levels were calculated as $\mathrm{nmol} / \mathrm{ml}[12]$.

\section{Statistical Analysis}

Descriptive statistical analysis was performed for all studied variables. The data were tested for normal distribution using the Kolmogorov-Smirnov test. Differences between the ESRD and control groups were investigated using the Mann-Whitney U test. The Spearman correlation coefficient analysis was used to examine the relationship between the serum anti-CA II antibody titers and other clinical parameters. $\mathrm{p}<0.05$ was considered significant. 


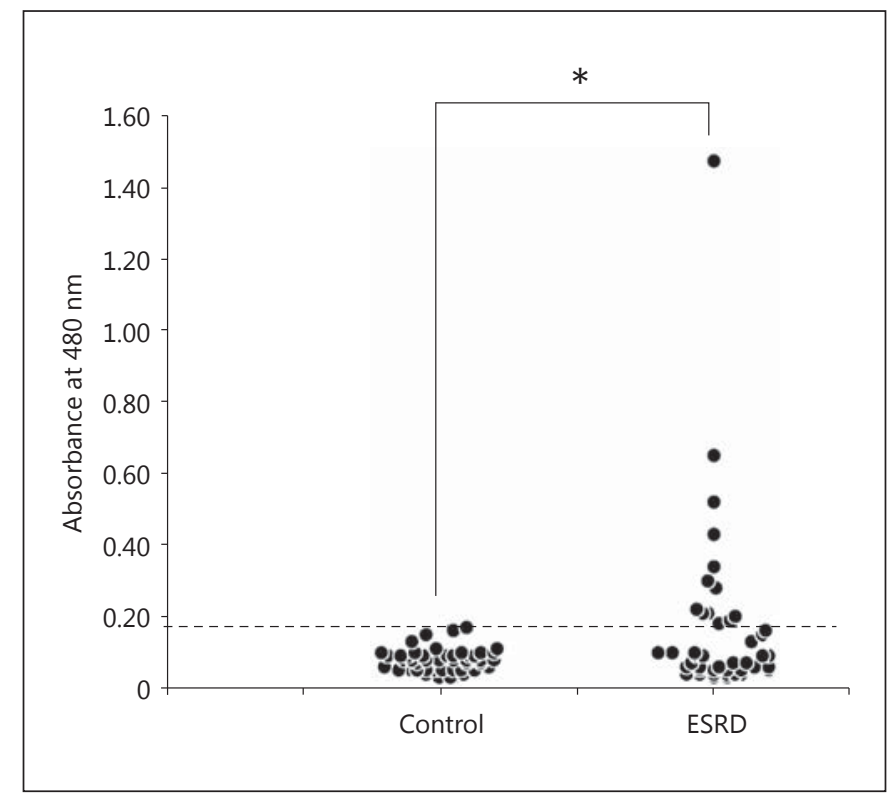

Fig. 1. CA II antibody titers in the control and ESRD groups. The dotted line indicates the mean +3 SD of control sera $\left(A^{480}=0.175\right)$. $* \mathrm{p}<0.05$, significant difference between the groups.

\section{Results}

The mean values of serum anti-CA II antibody, MDA, ghrelin, BUN, glucose and creatinine as well as the age and gender of the patients and controls are summarized in table 1, and the anti-CA II antibody levels in the ESRD patients and control subjects are shown in figure 1. The mean absorbance value for the control subjects was 0.079 $\pm 0.032(\mathrm{n}=45)$; absorbance values $>0.175$ (the mean absorbance $+3 \mathrm{SD}$ of control subjects) were defined as positive. Positive results were obtained in 13 of the 45 patients with ESRD (fig. 1). The mean absorbance value of the ESRD group $(0.170 \pm 0.237)$ was significantly higher than that of the control group $(p=0.035)$. Serum anti-CA II antibody levels showed a positive correlation with both BUN and creatinine concentrations $(\mathrm{r}=0.292, \mathrm{p}=0.034$ and $\mathrm{r}=0.269, \mathrm{p}=0.049$, respectively; table 2 ).

The serum MDA levels of patients with ESRD (1.16 \pm $0.89 \mathrm{nmol} / \mathrm{ml})$ were higher than those in the control group $(0.65 \pm 0.59 \mathrm{nmol} / \mathrm{ml} ; \mathrm{p}<0.001)$. There was also a positive correlation between MDA levels and anti-CA II antibodies in patients with ESRD $(\mathrm{r}=0.287, \mathrm{p}=0.028$; table 2).

The serum total ghrelin level in the control subjects was $6.50 \pm 9.14 \mathrm{ng} / \mathrm{ml}$ while that in the ESRD patients was $13.69 \pm 10.34 \mathrm{ng} / \mathrm{ml}$, and the difference was statistically
Table 1. The mean values of clinical parameters and laboratory findings in the study groups

\begin{tabular}{lccl}
\hline & Control & ESRD & $\mathrm{p}$ \\
\hline Number of subjects & 45 & 45 & - \\
Age, years & $51.26 \pm 10.7$ & $53.40 \pm 13.9$ & 0.334 \\
Gender, M/F & $17 / 28$ & $27 / 18$ & - \\
MDA, nmol/ml & $0.72 \pm 0.84$ & $1.11 \pm 0.84$ & $<0.001$ \\
Ghrelin, ng/ml & $6.50 \pm 9.14$ & $13.69 \pm 10.34$ & $<0.001$ \\
Anti-CA II Ab, ABSU & $0.079 \pm 0.032$ & $0.170 \pm 0.237$ & 0.035 \\
Glucose, $\mathrm{mmol} / \mathrm{l}$ & $4.8 \pm 1.26$ & $6.60 \pm 2.96$ & $<0.001$ \\
BUN, mmol/l & $5.2 \pm 0.84$ & $21.26 \pm 4.68$ & $<0.001$ \\
Creatinine, $\mu \mathrm{mol} / \mathrm{l}$ & $58 \pm 13.21$ & $1,044 \pm 693.05$ & $<0.001$ \\
\hline
\end{tabular}

$\mathrm{Ab}=$ Antibodies; $\mathrm{ABSU}=$ mean absorbance units

Table 2. Correlations between anti-CA II antibodies and other laboratory findings in ESRD patients

\begin{tabular}{|c|c|c|c|c|c|c|}
\hline & $\begin{array}{l}\text { Anti-CA } \\
\text { II }\end{array}$ & MDA & Ghrelin & Glucose & BUN & Creatinine \\
\hline \multicolumn{7}{|c|}{ Anti-CA II } \\
\hline $\mathrm{r}$ & - & 0.287 & -0.278 & 0.015 & 0.292 & 0.269 \\
\hline $\mathrm{p}$ & - & 0.028 & 0.032 & 0.465 & 0.034 & 0.049 \\
\hline \multicolumn{7}{|c|}{ Ghrelin } \\
\hline $\mathrm{r}$ & -0.278 & 0.169 & - & -0.005 & -0.055 & 0.003 \\
\hline $\mathrm{p}$ & 0.032 & 0.268 & - & 0.974 & 0.734 & 0.988 \\
\hline
\end{tabular}

significant $(\mathrm{p}<0.001)$. There was a negative correlation between the levels of ghrelin and anti-CA II $(r=-0.278$, $\mathrm{p}=0.032$; fig. 2).

In addition, within the ESRD group, the means of the parameters of patients with normal CA II antibody levels and those with positive CA II levels were compared. MDA, BUN and creatinine levels were higher but ghrelin and glucose levels were lower in the CA II antibody-positive group than in the normal-level CA II antibody group. However, these differences were not statistically significant ( $\mathrm{p}>0.05$, not included in the table).

\section{Discussion}

This study showed an increased immune response to CA II and also an association between CA II autoantibodies and MDA (an oxidative stress marker) in ESRD patients. Antibodies have been shown to develop against 


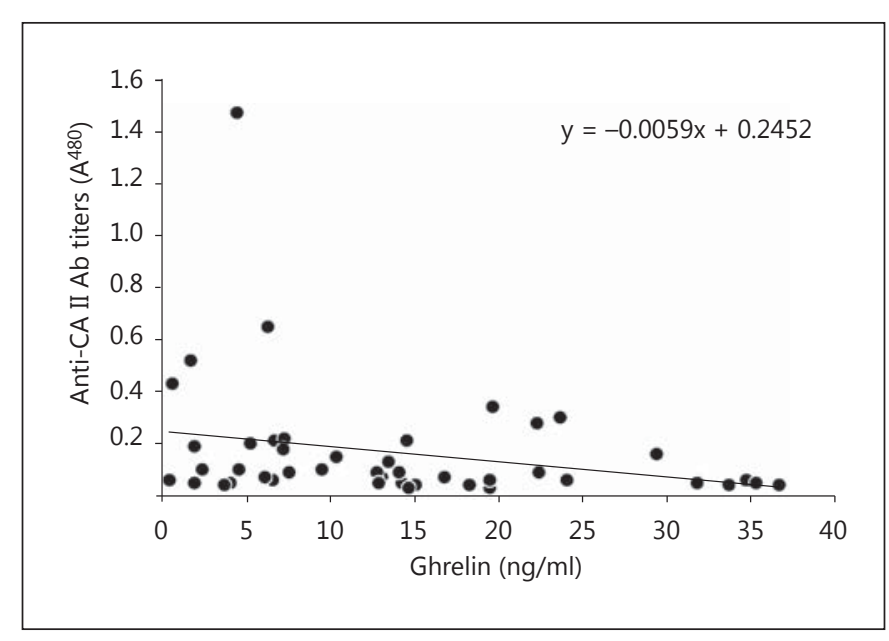

Fig. 2. The correlation between serum ghrelin and CA II antibody $(\mathrm{Ab})$ titers $(\mathrm{r}=-0.287, \mathrm{p}=0.032)$.

erythropoietin [19] and Tamm-Horsfall protein [20] in hemodialysis patients. Levels of CA II autoantibodies were higher in the hemodialysis patients than in the controls ( $\mathrm{p}<0.035$; fig. 1). Although similar results have been reported in several inflammatory diseases, such as rheumatoid arthritis, systemic lupus erythematosus and SJS, the mechanism by which CA antibodies form has not yet been fully explained $[3,4]$. General mechanisms of antibody formation may be responsible, and it has recently been reported that oxidative stress-related modifications may be involved [9].

We summarize here the mechanisms by which CA antibodies form in ESRD patients. (1) Lipid peroxidation end products, i.e. HNE (4-hydroxy-2-nonenal) and MDA, modify proteins and alter their antigenic properties [21]. The primary target of HNE in erythrocytes is CA II [22]. In particular, erythrocytes are exposed to both physical stress occurring during dialysis and oxidative stress caused by the factors mentioned above. CA II present in erythrocytes or damaged kidney tissue may acquire an antigenic property due to similar modifications. In agreement with this, we determined a positive correlation between CA II autoantibodies and MDA levels ( $\mathrm{p}=0.028$; table 2). (2) Oxidative stress and hemodialysis are also known to induce protein catabolism and apoptosis in ESRD [23]. It has been reported that apoptotic bodies are important in the formation of antibodies against intracellular proteins [24]. (3) The CA of Helicobacter pylori may trigger an autoimmune response against human CA II as an antigen [25]. A high prevalence of $H$. pylori has been found in hemodialysis patients. In addition, $H$. pylori in- fection reduces ghrelin production from the gastric mucosa and therefore lowers serum ghrelin levels [26]. In our study, we also observed a negative correlation between anti-CA II antibodies and ghrelin. (4) Four different CA isoenzymes located in different cell types and in subcellular locations are present in kidney tissue [2]. CA II autoantibodies might have formed against another antigenic CA isozyme because of molecular mimicry.

It is difficult to explain the potential roles of CA II autoantibodies in the pathology of ESRD. CA II, CA IV and CA XII are present in the human kidney. Cytosolic CA II is responsible for $95 \%$ of CA activity in the kidney. CA is responsible for bicarbonate reabsorption in the kidneys, $\mathrm{NH}^{+}{ }_{4}$ excretion and the acid-base balance [2]. The inhibition of CA II by autoantibodies has been demonstrated [27]. In addition, autoantibodies are known to be taken up into target cells via receptor-mediated (Fc receptor) and nonreceptor paths (electrostatic interactions and endocytosis) [24]. Antibodies entering into kidney tissue or filtered into the channels may cause renal tubular acidosis as a result of CA inhibition. Transporters that function with $\mathrm{H}^{+}$produced by CA can also be inhibited. A similar clinical picture has been reported in patients with primary SJS [7]. Renal tubular acidosis has been observed in these patients, and a significant correlation has been found between CA II antibodies and urine $\mathrm{pH}$.

Inflammation, cardiovascular complications and protein-energy wasting are the main sources of mortality in ESRD patients. Ghrelin is a peptide involved in all these different pathways. Ghrelin levels are high in ESRD, both as a decrease of breakdown in the kidney and as a defense mechanism against hunger $[16,17]$. Ghrelin has been reported to be important as a potential marker of mortality, and the death rate rises as its levels decrease [17]. In this study, ghrelin levels were higher in the ESRD patients than in the controls (table 1). CA II autoantibody titers were higher in ESRD patients. Together with this, the negative correlation of CA II antibodies with ghrelin (fig. 2) and its association with oxidative stress suggest its potential use as a mortality marker in ESRD patients. In addition, CA II autoantibodies were positively correlated with BUN and creatinine $(r=0.292, p=0.034$ and $r=$ $0.269, \mathrm{p}=0.049$, respectively).

\section{Conclusion}

In ESRD patients, the autoimmune response against CA II, oxidative stress and the ghrelin levels increased. Further studies are required in order to reveal the pos- 
sible mechanistic link between CA II autoantibody and oxidative stress, and the role of CA II autoantibody in the pathogenesis of the ESRD as well as to explore (if it exists) the potential prognostic value of CA II in ESRD.

\section{Acknowledgment}

We are grateful to Süleyman Türedi, Assist. Prof. and Dr. Seyit Hisoğlu for their technical support. This research was partly funded by the Karadeniz Technical University Research Fund (Project No. 8682).

\section{References}

1 Supuran CT: Carbonic anhydrases: novel therapeutic applications for inhibitors and activators. Nat Rev Drug Discov 2008;7:168181.

2 Purkerson JM, Schwartz GJ: The role of carbonic anhydrase in renal physiology. Kidney Int 2007;71:103-115.

-3 Inagaki Y, Jinno-Yoshida Y, Hamsaki Y, et al: A novel autoantibody reactive with carbonic anhydrase in sera from patients with systemic lupus erythematosus and Sjögren's syndrome. J Dermatol Sci 1991;2:147-154.

4 Alver A, Şentürk A, Çakirbay H, et al: Carbonic anhydrase II autoantibody and oxidative stress in rheumatoid arthritis. Clin Biochem 2011;44:1385-1389.

- 5 Alver A, Menteșe A, Karahan SC, et al: Increased serum anti-carbonic anhydrase II antibodies in patients with Graves' disease. Exp Clin Endocrinol 2007;115:287-291.

-6 Invernizzi P, Battezzati PM, Crosignani A, et al: Antibody to carbonic anhydrase II is present in primary biliary cirrhosis irrespective of antimitochondrial antibody status. Clin Exp Immunol 1998;144:448-454.

-7 Pertovaara M, Bootorabi F, Kuuslahti M, et al: Novel carbonic anhydrase autoantibodies and renal manifestations in patients with primary Sjögren's syndrome. Rheumatology 2011;50:1453-1457.

8 Nishi H, Tojo A, Onozato ML, et al: Anti-carbonic anhydrase II antibody in autoimmune pancreatitis and tubulointerstitial nephritis. Nephrol Dial Transplant 2007;22:1273-1275.

-9 Iuchi Y, Okada F, Onuma K, et al: Elevated oxidative stress in erythrocytes due to SOD1 deficiency causes anemia and triggers autoantibody production. Biochem J 2007;402:219227.
$>10$ Stepniewska J, Dolegowska B, Ciechanowski $\mathrm{K}$, et al: Erythrocyte antioxidant defense system in patients with chronic renal failure according to the hemodialysis conditions. Arch Med Res 2006;37:353-359.

-11 Lacotelli F, Canaud B, Eckardt KU, et al: Oxidative stress in end-stage renal disease: an emerging threat to patient outcome. Nephrol Dial Transplant 2003;18:1272-1280.

12 Devrim E, Erten S, Erguder IB, et al: Malondialdehyde and nitric oxide levels in erythrocytes from patients with systemic sclerosis. Med Princ Pract 2008;17:349-350.

13 Morena M, Delbosc S, Dupuy AM, et al: Overproduction of reactive oxygen species in endstage renal disease patients: a potential component of hemodialysis-associated inflammation. Hemodial Int 2005;9:37-46.

$>14$ Kurien BT, Scofield RH: Autoimmunity and oxidatively modified autoantigens. Autoimmun Rev 2008;7:567-573.

15 Mak RH, Cheung W, Purnell J: Ghrelin in chronic kidney disease: too much or too little? Perit Dial Int 2007;27:51-55.

16 Carrero JJ, Nakashima A, Qureshi AR, et al: Protein-energy wasting modifies the association of ghrelin with inflammation, leptin, and mortality in hemodialysis patients. Kidney Int 2011;79:749-756

17 Mak RH, Cheung W: Is ghrelin a biomarker for mortality in end-stage renal disease. Kidney Int 2011;79:697-699.

18 Yagi K: Lipid peroxides and related radicals in clinical medicine. Adv Exp Med Biol 1994;66: $1-15$.
19 El-Din MM, Attia FM, Labib SM, et al: Detection of circulating antierythropoietin antibodies in patients with end-stage renal disease on regular hemodialysis. Int J Lab Hematol $2010 ; 32: 336-343$

20 Work J, Andriole VT: Tamm-Horsfall protein antibody in patients with end-stage kidney disease. Yale J Biol Med 1980;53:133-148.

-21 Toyoda K, Nagae R, Akagawa M, et al: Protein-bound 4-hydroxy-2-nonenal: an endogenous triggering antigen of anti-DNA response. J Biol Chem 2007;282:25769-25778.

22 Uchida K, Hasui Y, Osawa T: Covalent attachment of 4-hydroxy-2-nonenal to erythrocyte proteins. J Biochem 1997;22:1246-1251.

23 Raj DS, Boivin MA, Dominic EA, et al: Hemodialysis induces mitochondrial dysfunction and apoptosis. Eur J Clin Invest 2007;37:971977.

24 Racanelli V, Prete M, Musaraj G, et al: Autoantibodies to intracellular antigens: generation and pathogenetic role. Autoimmun Rev 2011;10:503-508.

-25 Guarneri F, Guarneri C, Benvenga S: Helicobacter pylori and autoimmune pancreatitis: role of carbonic anhydrase via molecular mimicry? J Cell Mol Med 2005;9:741-744.

26 Sugimoto M, Yasuda H: Association with $\mathrm{He}$ licobacter pylori infection and ghrelin level in hemodialysis patients. Kidney Int 2011;80: 894.

27 Botrè F, Botrè C, Podestà E, et al: Effect of anti-carbonic anhydrase antibodies on carbonic anhydrase I and II. Clin Chem 2003;49:12211223. 